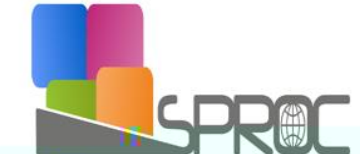

Sciencepark Research, Organization \& Counseling

3

Educational Researches Journal $7 \quad 3 \quad 3$

Contemporary

3 
systemic approach

3

social system 
1.1. The empirical analysis of school performance factors

Invalsi test

designed and administered by

Italy's National Institute for the Evaluation of the Country's Educational System
INVALSI tests are , i.e.

Invalsi tests

1.2. Method

1.3. The composition of sample

Licei

Campania Educational Department.

1.4. Analysis of principal components (PCA) 
elbow

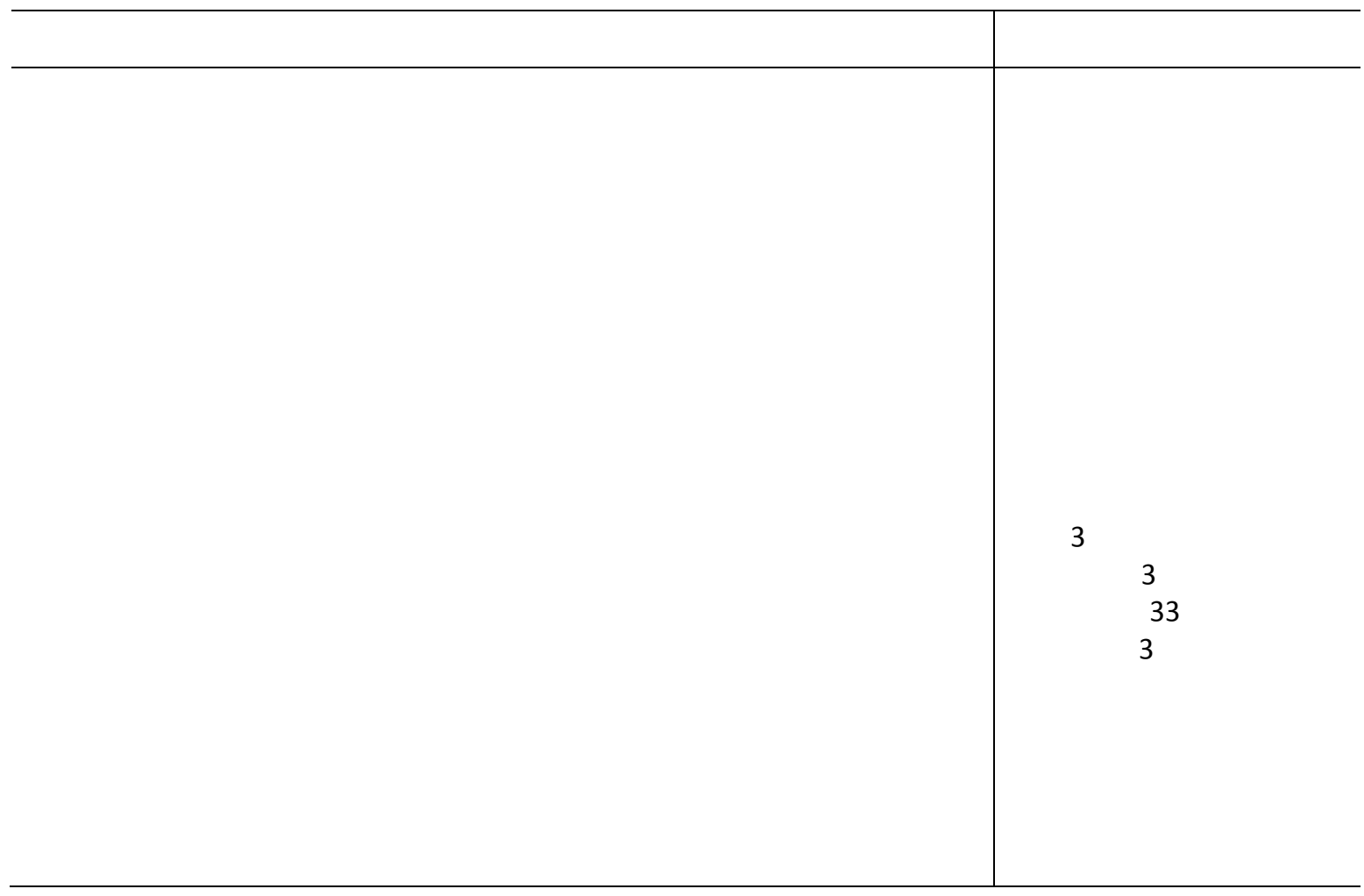


3

\begin{tabular}{l|l|l|l}
\hline & & & \\
\hline 3 & 3 & 3 & 3 \\
& 33 & & 3 \\
& & & \\
& 3 & 3 & \\
& 3 & & \\
& & 3 & \\
\hline
\end{tabular}

33

3

3

3

3

3

33

3

- 3

3

3

3

$\begin{array}{ll}- & 33\end{array}$

- 3

$\begin{array}{ll}- & 3\end{array}$

3

33

$-$

$\begin{array}{ll}- & 333 \\ - & 33\end{array}$

$-$ 


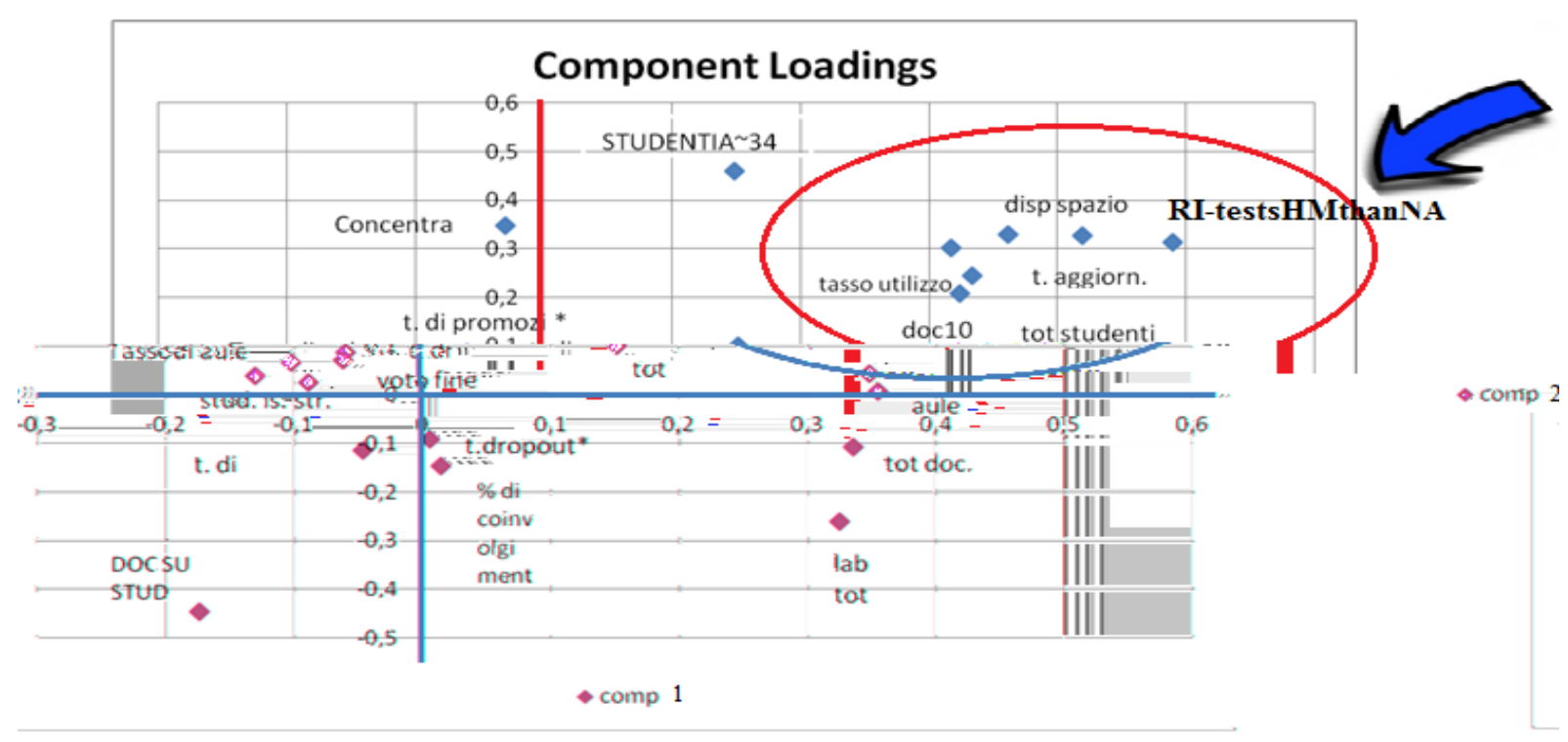

1.5. Multiple regression 


\section{Student's $t$}

\begin{tabular}{llll}
\hline & & & \\
\hline & & & 33 \\
3 & 3 & 3 & \\
& 3 & 3 & 3 \\
\hline
\end{tabular}

3

3

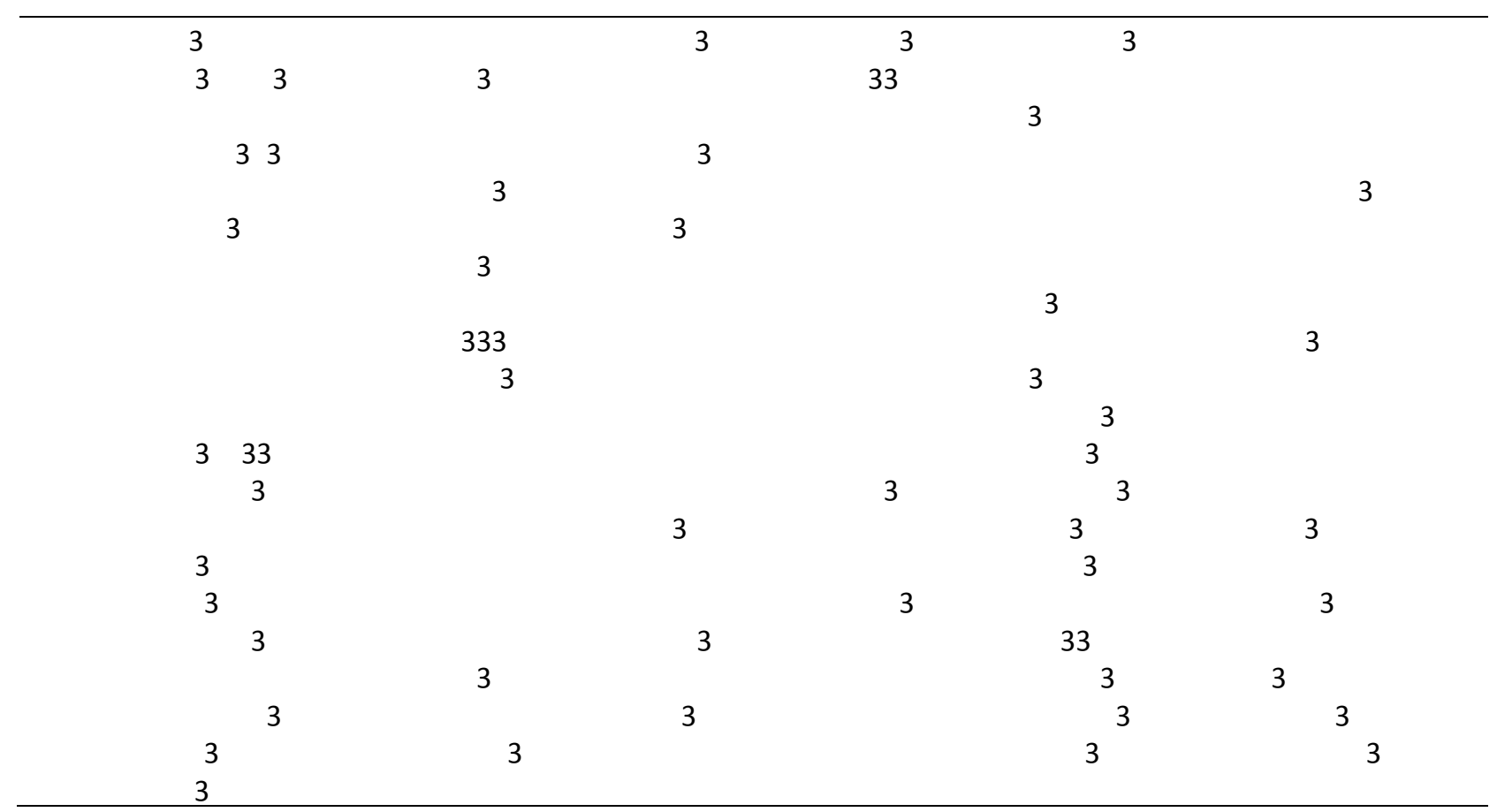

Availability

of library spaces Availability of labs Rate of teachers' professional updating Rate of use of labs Teachers who have remained in the same school for more than 10 years 
Availability of Library spaces Availability of labs 3 Rate of teachers' professional updating Rate of use of labs Teachers who have worked in the same school for more than 10 years.

passed the INVALSI tests with a score higher than the national average" 
Estimating Strength of a DDoS Attack Using Multiple

Psychometrika, 30

Educational Research Bulletin. Taylor \& Francis, $33 \quad 3$

Principal Component Analysis

Measurement 20

Educational and Psychological

Administration Research and Theory 15

Journal of Public

The Social System

Performance management in the public sector

Psychometrika

4133 